Humboldt and K. Ritier. In spite of the great progress made in geographical thought in recent decades, there is a noticeable lack, at least in English, of objective geographical studies of most parts of the world. British geography has progressed more on the study of topics than that of regions. Prof. Darby spoke of the importance of more regional study, especially with a historical bias, since the character of a region is based not merely on physical and economic facts, but also on the legacies of succesfive generations of its inhabitants.

\section{Documentation in.Switzerland}

A sEcond pompletely revised and augmented edition af " threr durch die Schweizerische Dokumepat op', by Theodore van Schelven (Amsterdam: Kopplos bublishing Co., Keizersgracht 133. 1 dollar), has now been published by the Swiss Association for Documentation. The pamphlet has proved of considerable value to Swiss research workers during the war years, since it quotes collections containing literature lacking in the large Swiss scientific libraries and which could not be included in the general catalogue of the Swiss National Library. The new edition lists 227 documentation centres arranged by subject according to the Universal Decimal Classification, together with alphabetical name, subject and place indexes, and a list of users of the Universal Decimal Classification. The introduction includes brief notes on the Swiss Association for Documentation, the Swiss Association of Librarians, the general catalogue and information service of the Swiss National Library, Berne, on documentation terminology, the standardization of documentary aids and a bibliography of publicutions of Swiss authors on documentation, biblingraphy and the decimal classification.

\section{Silicon Carbide Non-ohmic Resistors}

During the past de ade, resistors having silicon carbide as tos ing chant and characterized by a striking 4 part from Ohm's law-the current passed ing propertional to the fourth or fifth power of th itplied viljage-have become available commfoldy and are now widely used in many fields of lectrical engineering. Their development was first stimulated by the requirements of surge diverters (lightning arresters) for overhead power transmission lines, but success in this application had led to their use for the protection, /at much lower voltages, of the highly inductive coils found in electrical machinछry, contactors, clutches, brakes, relays, etc. An important advantage arising from the limitation of the peik voltage developed when such coils are disconnected from the supply is the reduction of the sparking at opening contacts, and of the radio interference to which such sparking gives rise. This method of spark quenching has received particular attention in connexion with telephone relays, where the preservation of contacts is of great importance. Silicon carbide resistors have also found application for the protection of radio transmitting and receiving circuits and of electrical instruments, and for scale modification in the latter; in metadyne systems, where they permit practically any desired main motor characteristic to be obtained; and in non-linear bridge circuits. The characteristics and limitations of these resistors, and the principles governing their application, are discussed in a recent paper by Messrs. F. Asliworth, W. Needham and R. W. Sillars (J. Inst. Elect. Eng., 93, Part 1, No. 69; Sept. 1946), with which is associated an extensive discussion.

\section{Research on Multiple Sclerosis}

THE Association for Advancement of Research on Multiple Sclerosis, the address of which is New Yark Academy of Medicine Building, Fifth Avenue and 103rd Street/New York 29, N.Y., has been formed by a group of multiple sclerosis patients, with their many frionds and relatives, in co-operation with some of the leading neurologists of North America. Its gims are : (1) co-ordination of research efforts on myltiple sclerosis; (2) collection of statistics on its prevalence and geographical distribution; (3) to act as a clearing house for information on this disease; (4) education of the public on the problem of multiple sclerosis; (5) collection of funds to stimulate and support research on multiple sclerosis and allied diseases. For the present, the Association proposes to conduct a membership drive for the enrolment of multiple sclerosis patients as well as the public, in an endeavour to obtain more definite statistical data on the prevalence of the disease. Dr. Tracy Jackson Putnam, director of Services of Neurology and Neurological Surgery, Neurological Institute of New York, is the honorary chairman of the Association.

\section{Institution of fivil Engineers \\ 6.6}

SIR WILTIAM fulconow, in his presidential address to the Instify on of Civil Engineers on November 5, reviefer of accomplishments of the Institution, mor fasticalarly during the past fifteen of the 128 ont that it has been in existence. Not every eppin will agree with Sir William's opinion that too much reliance should not be placed on theoretical knowledge. Engineering is an applied science, and therefore the provision of facilities for practical training, as distinct from practical experience, cannot receive too much attention from the Institution; but it is impossible for the engineer to have too much knowledge of the fundamentals or theoretical basis of his science. The civil engineer's record during the War when, as Sir William points out, 'Mulberry' and 'Pluto' were designed, would have been even more spectacular if fundamental knowledge, essential in dealing with new and complex problems, had been more widespread.

Another matter of considerable moment, dealt with by Sir William in his address, was the difficulty met with to-day in presenting the views of the profession as a whole on matters of public interest, due to the large number of engineering institutions which exist. While the Institution's present policy of setting up sectional divisions specializing in the various branches of professional work may make unnecessary the ereation of more institutions, it is unlikely to do much to encourage the existing smaller institutions to amalgamate. The value of amalgamation which would enable engineers, who should form a most influential section of the community, to speak with one voice, is recognized by all but a very small minority. That small minority, however, inevitably includes the most influential and hard-working members of the smaller institutions, who are naturally governed by a sense of loyalty to their own organisations. It will need a measure of self-sacrifice and a sense of wider loyalty to the profession as a whole to right the position.
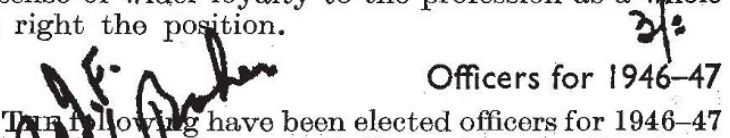

'TIS f I o flg have been elected officers for 1946-47 of thIntution of Civil Engineers: President, Sir Willam Halcrow; Vice-Presidents, Sir Frederick 